\title{
The structure of disaster resilience: a framework for simulations and policy recommendations
}

\author{
J. H. Y. Edwards \\ Department of Economics and Disaster Resilience Leadership Academy, \\ Tulane University, New Orleans, LA 70118, USA
}

Correspondence to: J. H. Y. Edwards (edwards@tulane.edu)

Received: 13 August 2014 - Published in Nat. Hazards Earth Syst. Sci. Discuss.: 8 September 2014

Accepted: 11 March 2015 - Published: 13 April 2015

\begin{abstract}
In this era of rapid climate change there is an urgent need for interdisciplinary collaboration and understanding in the study of what determines resistance to disasters and recovery speed. This paper is an economist's contribution to that effort. It traces the entrance of the word "resilience" from ecology into the social science literature on disasters, provides a formal economic definition of resilience that can be used in mathematical modeling, incorporates this definition into a multilevel model that suggests appropriate policy roles and targets at each level, and draws on the recent empirical literature on the economics of disaster, searching for policy handles that can stimulate higher resilience. On the whole it provides a framework for simulations and for formulating disaster resilience policies.
\end{abstract}

\section{The structure of disaster resilience}

Resilience is a term with many connotations and definitions in the disaster literature. This paper integrates the components of resistance to and recovery from disaster into a model of resilience. The paper begins by defining resilience formally and introducing a mathematical form for resilience. I then introduce the notion of interdependent resilience layers and place the mathematical form into this layered structure. I identify important evidence in the empirical economic literature that a layered response structure exists. The empirical literature also reveals influence points where outside intervention can improve resilience. I conclude by using some of this empirical evidence to illustrate how the multilayer model would work in the context of financial resistance to and recovery from disaster.
The paper is organized in the following manner. Section 1 lays out the intellectual roots of resilience by tracing the migration of its meaning through material science and ecology and by explaining why and how this meaning must be further modified to adequately describe human systems. The first finding is that resilience is a new idea, not just a new word. I demonstrate how it can be defined narrowly enough and with enough technical precision to make it a useful tool for theoretical and empirical studies of disasters.

Section 2 develops a formal definition of resilience and sets it within an economic context. The second finding is that resilience is best viewed as a structural characteristic of a multilayered, hierarchical system. Resilience "layers" include individual people and sets of people organized into families, local organizations, businesses, local governments, national governments, and international organizations. All layers have not only their own native resilience capacities but also variable abilities to draw on resources from higher levels in the system. This idea of hierarchically layered resilience is developed into a mathematical framework that can be used for empirical estimation and mathematical simulations. In order to appeal to a wide, multidisciplinary audience, the more substantive technical developments are laid out in separate sections that can be skipped by non-technical readers without loss of continuity.

Section 3 reviews the recent empirical economics literature for evidence of resilience and of its multilevel structure. The third finding of this paper is that the literature on the economics of disasters has produced a myriad of significant empirical results on why disaster resilience differs. There is a growing body of empirical studies of resilience that ask many important questions. However, this literature is devel- 
oping without a formal framework to guide hypotheses and organize findings. I document that these results can be clearly organized by the resilience model that this paper proposes. Furthermore, the empirical evidence is consistent with the predictions of the layered resilience model.

Section 4 demonstrates how the model can be used to organize and make sense out of the myriad bits of empirical evidence on disasters that are rapidly emerging. It uses the financial sector to illustrate how the theoretical model can shape empirical evidence into a framework that can be used to describe and simulate a resilient system, a framework for recommending policies that will increase global resilience to disaster.

\subsection{The intellectual roots of resilience}

"Resilience" is a relatively new addition to the disaster analysis vocabulary, so there is still substantial confusion about what it means (UNDP, 2012; USAID, 2013a; KubitchekBujones, et al., 2013; Frankenberger et al., 2012; Thieken et al. 2014). The confusion has led some researchers and practitioners in the field to wonder if resilience is just a fashionable new term with no new content (for instance, Cabot-Venton, et al., 2012; Levine, et al., 2012).

Resilience made its way into the social sciences from ecology, where it first appeared in the 1970s. The term was not adopted but adapted by ecology from material science. It underwent substantial modification over the course of more than 2 decades. For instance, the ability of materials to absorb energy from a strictly external stimulus, store it as potential energy, and then release that same energy later is central to the definition of resilience in physics. Yet this word has never had that connotation in ecology. In ecology and in the fusion of ecology with sociology, stress is something different. It may include energy from an external source, but it can also arise from within the system (for instance Gallopin, 2006). Also, in material science resilience is the property of a single material (say the resilience of aluminum 6061), but in ecology the same word is used to describe complex systems that are composed of many interdependent actors, like the many life forms that comprise the ecosystem of a freshwater pond. This is another major adaptation of the concept.

We can expect some give and take before the disaster literature settles on a definition of resilience. After all, it took over 2 decades for ecologists to agree on one. The two papers most often cited for introducing the concept into ecology, Holling (1973) and Gunderson (1999), actually define resilience in opposite ways. Holling felt that ecology had focused too narrowly on stability, which he defines as the ability of an ecological system to return to its pre-shock equilibrium after an external disturbance. So he contrasted stability to the persistence of interspecies relationships within a system that has multiple equilibria and called this contrasting mechanism resilience. Holling-resilience thus describes flexible, multiple-equilibrium ecological systems. His definition describes a mechanism that leads to a lower probability of species extinction but does not require the system to return to its pre-stimulus state. In fact higher Holling-resilience means less stability (p. 17) ${ }^{1}$.

In the other paper that is often cited for introducing resilience into the ecological lexicon, Gunderson (1999) defines resilience as "the ability to return to an equilibrium following a perturbation; it is quantified in return time" (p. 3). Notice that this ability to return to an identical equilibrium after stress is the way that Holling (1973) defined "stability"; it is what Holling specifically states is not resilience. Ecology finally settled on Gunderson-resilience as the default definition (Gunderson, et al., 1997).

Such back-and-forth exchanges are not confined to the field of ecology and the study of disasters. In The Structure of Scientific Revolutions, Khun (1962) writes that "the early developmental stages of most sciences have been characterized by continual competition between a number of distinct views of nature, each partially derived from, and all roughly compatible with, the dictates of scientific observation and method" (p. 4). The introduction of new words can serve the purpose of moving a discipline forward by making scholars aware of assumptions that are implicit in existing frameworks, assumptions that may not always hold in practice. This is part of the normal process of scientific inquiry. It took a long time for ecologists to agree on what resilience means for their discipline; many years may pass before disaster analysis agrees.

\section{A model of resilience}

This four-part section lays out a model of disaster resilience. Parts 2.11 and 2.2 define the term and parts 2.3 and 2.4 incorporate the definition into a multilevel system. Parts 2.1 and 2.3 are informal statements that lead to a schematic model of the sort common to the interdisciplinary resilience literature. Parts 2.2 and 2.4 contain more formal definitions. Readers who are not interested in technical details may skip these parts without loss of continuity.

\subsection{Informal definition of resilience}

The first clarification that is necessary for bringing the concept of resilience from ecology into the study of disasters is to clearly state at the outset that we are referring to the Gunderson (1999) definition that involves full recovery to the pre-shock state, and not the Holling (1973) concept of survival through multiple equilibria.

There are clear reasons to prefer Gunderson-resilience. When dealing with disasters that affect human populations,

\footnotetext{
${ }^{1}$ Holling's examples involve open ecological systems like the interaction between the spruce budworm and fir, spruce, and birch trees in eastern Canada, with predator-prey relations that can exist in various predator-prey population balances.
} 
Holling-resilience does not fit because Holling-resilience does not consider human ethics in calculating optimal equilibrium recovery strategies. In Holling-resilience the existence of multiple equilibria is an unambiguously desirable property if this adds to the long-run survival of a system. The study of human reaction to and recovery from disaster can not be so dispassionate about welfare redistribution, about large changes in population size, or about one group benefitting at the expense of others. Ethical norms forbid the inclusion of survival strategies that depend on dramatic redistributions of welfare. Therefore, when we talk about the resilience and recovery of a human population affected by disaster, we are referring to Gunderson-resilience, in which it is optimal for individuals to fully recover. We may talk about recovery that also improves the structure that existed before the disaster, about coming back "better", or about building in more resilience into the recovered state (Thieken et al., 2014), but we shall always need to quantify and compare pre- and postdisaster states for each of the actors within the system. We will need to say something about the degree of their return to their pre-disaster status, exactly.

Resilience is the latest of three words that have entered the study of disaster and the economics of poverty, the others being sustainability and vulnerability. Sustainability entered in response to the myopic post-war focus on economic growth of programs that were intensive in natural-resource depletion and to the social strain caused by rising income inequality (Club of Rome; 1972, United Nations, 2012). In this sense they were not sustainable in the long run. Vulnerability was first introduced in order to emphasize a down-side threat of poverty (Calvo and Dercon, 2005), that poor and non-poor were not disjoint sets. Its core purpose is to explicitly acknowledge uncertainty over different states of the world by characterizing the relation of those states to critical thresholds (poverty lines) and by the probabilities associated with each possible future state. Resilience is a dynamic concept that has sustainability over the long term and vulnerability to external shocks at its core, but goes on to ask a new question. If a shock pushes someone below a threshold (poverty, hunger, etc.) does he have the ability to return to the preshock state? If so, then how quickly?

In the resilience model that I develop here actors exist within a sociopolitical system, and they are exposed to low-frequency, high-impact adverse events called "shocks". Shocks can be ranked along a severity continuum. Some examples of such continuums include Richter scale, wind speed, flood depth, radiation exposure, length of conflict, and dollars of damage.

Resilience is defined here to encompass two properties of actors. The first property will be called resilience capacity. It is quantified as the maximum shock severity that an actor can successfully recover from. The second property is resilience speed and is measured in units of time to recovery after a disaster. Resilience speed will typically depend on resilience capacity and on shock severity. Resilience is
Resilience Functions

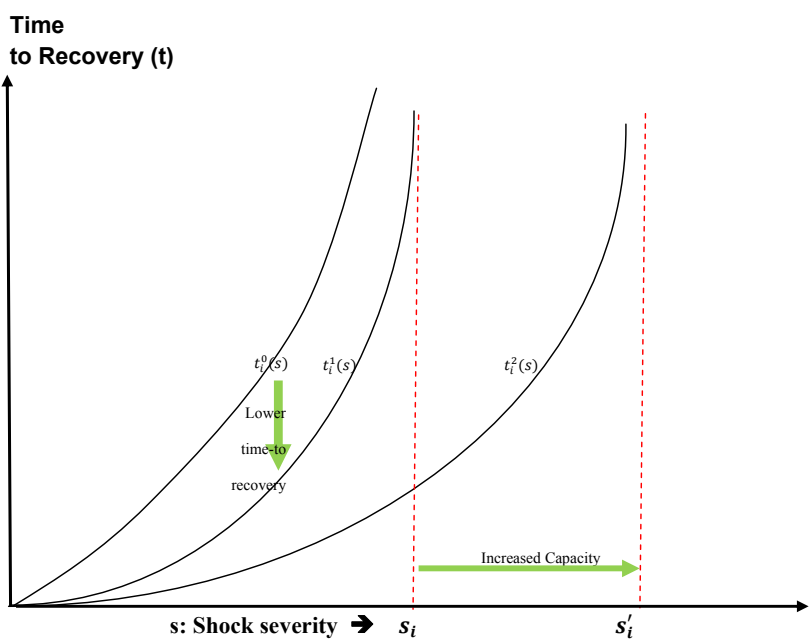

Figure 1. Three examples of resilience functions are show; time to recovery is a function of shock severity and of capacity. In relation to the reference function $t^{0}(s), t^{1}(s)$ shows the same capacity to withstand a shock up to severity level $s_{i}$, but $t^{1}(s)$ exhibits greater recovery speed since, for any $s<s_{i}$, we have that $t^{1}(s)<t^{0}(s)$. The third function $t^{2}(s)$ shows an increase in capacity. Shocks in the range $s_{i}<s<s_{i}^{\prime}$ have a finite recovery time.

captured by resilience functions, depicted in Fig. 1, which plot recovery time " $t$ " against shock severity " $s$ ". Resilience capacity " $c$ " is measured in the same units as severity. As severity approaches capacity, recovery time rises exponentially. The second relation drawn in Fig. 1 shows a resilience function that has been enhanced. It has the same capacity as the first function, but a lower recovery time at every severity level below capacity. The third function drawn is for a resilience function that has higher capacity.

\subsection{Formal definition of resilience}

A country is a set of $\mathrm{N}$ people together with an organization of those people into subsets and sets of subsets (classes) called "actors". A function $\zeta$ assigns actors to subsets that are organized in hierarchical levels $L_{j} \in L$ called layers. $\zeta$ might read much like a census questionnaire with arguments such as parents, religion, and place of residence. Formally, the layers $L$ are a measure on the set of people in a country. Layers are indexed by $j \in\{1,2, \ldots, j\}$. Each actor " $i$ ", $i \in\left\{1,2, \ldots, n_{j}\right\}$ within a layer $L_{j}$ is described by an initial level of welfare $v_{i j 0}>0$, by a native resilience capacity $c_{i j}$, and by a resilience speed given by the function $t_{i j}\left(c_{i j}, s\right)$. Resilience capacity and resilience speed are defined below.

Actors are exposed to an external shock of stochastic severity $s \in(0, z)$ and probability density function $f(s)$ that reduces their pre-shock initial welfare to $v\left(v_{i j 0}, c_{i}, s\right) \leq v_{i j 0}$. The native resilience capacity of actor $i, c_{i}$, is measured in the same units as $s$ and defined as the ability of actor $i$ to 
withstand shocks up to level $c_{i}$ without drawing on higherlevel resources, that is, without drawing on the resources of levels $L_{k}$, for $k>j$, so $v\left(v_{i j 0}, c_{i j}, s\right)=0$ for $s \geq c_{i}$. The resilience function $t_{i j}\left(c_{i j}, s\right)$ describes the time it takes for level $L_{j}$ to return to its previous (pre-shock) state, given that $s<c_{i j}$. The resilience function is assumed to have the following properties:

$t\left(c_{i j}, 0\right)=0, \forall c_{i j}$

$\frac{\partial t_{i j}}{\partial s}>0, \quad \frac{\partial^{2} t_{i j}}{\partial s^{2}}>0, \quad$ for $s \in\left(0, c_{i j}\right), \quad$ and

$t_{i j} \rightarrow \infty \quad$ as $s \rightarrow c_{i j}$

The native resilience function is depicted as $t_{i j}^{0}\left(c_{i j}, s\right)$ in Fig. 1. It increases at an accelerating rate in shock severity $\mathrm{s}$ and as $\mathrm{s}$ approaches $c_{i j}, t_{i j}^{0}\left(c_{i j}, s\right)$ goes to infinity.

Several functions can satisfy these resilience function conditions. One modeling option is to use a two-parameter cumulative density function $F(\mu, \sigma)$, such as the lognormal density, ${ }^{2}$ setting the location parameter $\mu=\ln \left(\frac{s}{c_{i}}\right)$. But this comes at the cost of building in the assumption that no event is sufficiently severe to completely destroy $v_{0}$. It will therefore generally be preferable to use the specifications like those in Eqs. (2) and (3), below.

One of the simplest options is

$t\left(c_{i j}, s\right)=\frac{s}{c_{i j}-s}$.

Another, logarithmic, modeling choice is

$t_{3}\left(c_{i j}, s\right)=\ln \left(1+\frac{s}{c_{i j}-s}\right)=\ln \left(\frac{c_{i j}}{c_{i j}-s}\right)$.

More general forms of the resilience function can allow for flexible recovery speed without affecting capacity. For instance Eq. (2) can be generalized to $t_{2}\left(c_{i j}, s\right)=\frac{a \cdot s}{c_{i j}-s}$ and Eq. (3) to $t_{3}\left(c_{i j}, s\right)=a \cdot \ln \left(\frac{c_{i j}}{c_{i j}-s}\right)$. A reduction in the parameter " $a$ " leads to a more rapid recovery without affecting capacity, as in the shift from $t_{i j}^{0}\left(\mathrm{c}_{i j}, \mathrm{~s}\right)$ to $t_{i j}^{1}\left(\mathrm{c}_{i j}, \mathrm{~s}\right)$ in Fig. 1 . The parameters $a$ can be thought of as accommodating location or place differences, for instance shoreland versus inland. For simplicity, I will henceforth assume that $a=1$ and that all changes in the resilience technology $t\left(c_{i j}, s\right)$ affect both capacity and speed of recovery.

The concepts of resilience, capacity, recovery time, and damage are linked, but how? Dropping subscripts for convenience, let " $r$ " be the time preference or discount rate, $v_{0}$

\footnotetext{
${ }^{2} \mathrm{~A}$ similar approach is used in earthquake engineering for the construction of fragility curves (for instance Zetner et al., 2008). The difference is that fragility curves model the $(0,1)$ probability that a a structure will fail, whereas here we are interested in measuring the continuous variable $v\left(v_{0}, c_{i}, s\right)$ that describes the proportion of a welfare measure that survives an external shock.
}

the initial value of pre-disaster well-being, and $v\left(c, s, r, v_{0}\right)$ be the value of post-disaster well-being. Then the link between these is given by $v\left(c, s, r, v_{0}\right) e^{r t}=v_{0}$, which measures the value of post-disaster welfare as a function of its pre-disaster value, of the discount rate and of time to recovery as given by the resilience function $t(c, s)$. The post-disaster value is thus $v\left(c, s, r, v_{0}\right)=v_{0} e^{-r t}$. "Damage" is the decrease in initial value caused by the disaster, namely $D\left(c, s, r, v_{0}\right)=v_{0}-v\left(c, s, r, v_{0}\right)=v_{0}\left(1-e^{-r t}\right)$, and percent damage is simply $d(c, s, r)=\left(1-e^{-r t}\right)$. The convenience of resilience function specification Eq. (3) now becomes evident. Using $t(c, s)=\ln \left(\frac{c}{c-s}\right)$, we obtain $v\left(c, s, r, v_{0}\right)=v_{0} e^{-r t}=v_{0}\left(1-\frac{s}{c}\right)^{r}$ and percent damage is simply $d(c, s, r)=\left(1-\frac{s}{c}\right)^{r}$.

\subsection{Informal description of resilience layers}

In this model, societies are sets of individuals that are partitioned into subsets called actors. These subsets are layered hierarchically, ranging from the individual person (a set of one member) through sets of families, local organizations, local governments, and national governments. National governments can belong to sets called international organizations that operate in an international system. Subsets of actors within this system may be exposed to one or more adverse events called external shocks.

The difference between human and ecological resilience to disaster lies in the forces which define paths to equilibrium, and these forces arise from the relations between subsets of the population. Absent external stimuli, ecological system equilibria are largely driven by anonymous predator-prey relations between actors. Though it may be tempting to extend the predator-prey analogy to human society, human systems are nevertheless fundamentally different from ecological ones in this respect. Individual people exist within groups that are layered in a loose hierarchy of levels. Higher levels provide assistance to the lower ones when lower-level capacity is breached: person, family, private organizations, local government, national government, and international community. Upwards from any of these levels, an individual actor interacts with only a small subset of the actors in the next layer above, and frequently with only one of them. For instance most people have only one family, that family lives in a place with one local government, and that local government deals with a single national government.

This interdependent organization of people into hierarchical subsets leads naturally to the notion of resilience levels that are related to one another in a hierarchically organized structure. Actors at each level in the system (people, families, local governments, and national governments) initially respond to shocks by calling on resources that are properly their own, their native resources. If the shock is large, they may also be able to call upon a qualitatively different set of resources from the levels above them. Each actor's native re- 
sources translate into a native capacity to withstand adverse events and into a native recovery speed. When placed within the system, however, actor capacity and recovery speed depend not only on this native capacity but also on access to resources from higher levels, its systemic resources.

For example, if a woman is injured, her capacity to survive and the speed of her recovery will depend on individual characteristics like age, weight, height, education, savings, and general health. Similarly, the ability of different cities to withstand a magnitude 7.0 earthquake and the speed of their recovery will differ, depending on their native resources like local geography, the quality of local construction, their stocks of emergency response equipment and personnel, and their experience with similar disasters.

The crucial difference with ecological system resilience is the cooperative manner in which actor resilience is linked. The injured woman may nurse a minor injury on her own, but if the injury is sufficiently serious her recovery will also depend on the resources of her family, and on the quantity, efficiency, and training of first responders employed by local organizations. If enough people in her city are injured at the same time, the city can call on state or national resources. In addition to native resources, human actors at every level can draw on resources from higher levels when the severity of adverse events approaches or exceeds their native capacity to withstand external shocks on their own.

When looking through this system from the bottom, one sees that systemic resources flow down through a single channel, actor to actor. But when looked at from the top of the hierarchy, the plurality of actors at each level is evident. Each actor below is a node connected to many other actors at the next level down. Connections grow factorially from level to level. This plurality of actors enables the higher level to act. When an external shock strikes part of the network, the higher level contributes to resilience by redistributing resources among lower levels. This ability to reorganize and redistribute away from less affected actors is what gives the higher level power to augment lower-level native capacity. A higher level thus becomes powerless when all of its constituent parts are affected by disaster. Its capacity is the sum of the capacities below it.

Figure 2 illustrates this resilience structure with six resilience layers. The horizontal arrow along the bottom of Fig. 2 indicates $s$, the event severity axis. The dotted, black vertical arrows and the letters $C_{1}$ through $C_{5}$ mark capacities, i.e., the severity of adversity that each level can withstand without recourse to the systemic resources. These are the native resilience capacities for each level. For instance, if a disaster removed access to the central governments but left the sub-national system intact, actors in this system would be able to withstand events up to severity level $s=C_{4}$. The large arrows indicate the direction of demand for resources. Each level is color-coded. Native resources are listed in the large rectangle at each level. These are labeled $X_{1}$ through
$X_{6}$, for use in the more formal development of the model that follows. ${ }^{3}$

Systemic resources can directly augment some of the native resources, but not all of them. Color-coded "influence points" in Figure 2 illustrate examples of where higher levels can exert influence, offer help, or inject resources. Point colors correspond to the level of the same color, as indicated in the legend at the bottom. Our injured woman example would be at the level $L_{1}$. At this level education is a native resource. Points indicate that it can be affected by the family and by local and federal governments. Disaster awareness is also a personal resource, and the first point next to it indicates that local governments can enhance it. In contrast, age is a native resource, but it can not be changed or influenced by any systemic resources.

Upper levels affect resilience by decreasing time to recovery and/or by increasing capacity. These separate effects on a lower level are depicted in Fig. 1 in relation to an initial resilience function $t_{i}^{0}\left(c_{0}, s\right)$. The function to the right of it, $t_{i}^{1}\left(c_{0}, s\right)$, shows greater efficiency in the utilization of a given capacity. It has the same capacity as $t_{i}^{0}$ but a lower time to recovery for any disaster with severity $s \leq c$. The function $t_{i}^{2}\left(c_{2}, s\right)$ illustrates what happens to $t_{i}^{0}$ when its native capacity is increased from $c_{0}$ to $c_{1}$.

\subsection{Formal description of resilience layers}

To illustrate the systemic view of resilience ${ }^{4}$, it is helpful to consider a simplified model. Assume that there are " $n$ " disaster response levels. Every layer " $j$ " has a resilience resource of its own, $X_{j} \geq 1$, and for $j \in\{1, \ldots,(n-1)\}$ may also have access to the resilience capacity $C_{j+1}$ of the layer immediately above it. The topmost, $n$th layer ( $n=6$ in Fig. 2 ) has no higher level, and so this relation is simply $C_{n+1}=1$.

The capacity of layer $i$ is given by

$C_{i}=C_{i}\left(X_{i}, C_{(i+1)}\right)$,

where it is assumed that $C_{i}$ is differentiable, monotonically increasing, and concave in both arguments. This holds at all layers, so Eq. (4) may be rewritten recursively purely as a function of native resources:

$C_{i}=C_{i}\left(X_{i}, X_{(i+1)}, X_{(i+2)}, \ldots, X_{(n-1)}, X_{n}\right)$.

\footnotetext{
${ }^{3}$ The lists of resources are meant to be illustrative, not exhaustive.

${ }^{4}$ To be fully general, we must admit the possibility that systemic resilience at any given level can be lower than native resilience. Two examples are taxation and the forceful drafting of young men during civil strife. These actions strengthen government but weaken the resilience of families. This is obviously a very interesting and relevant topic on its own, but for the purpose of simplifying the exposition of focus here, I abstract from such negative interventions and concentrate on the positive ones. Interventions from above are henceforth treated as "outside help" that adds to the native resilience of lower levels.
} 


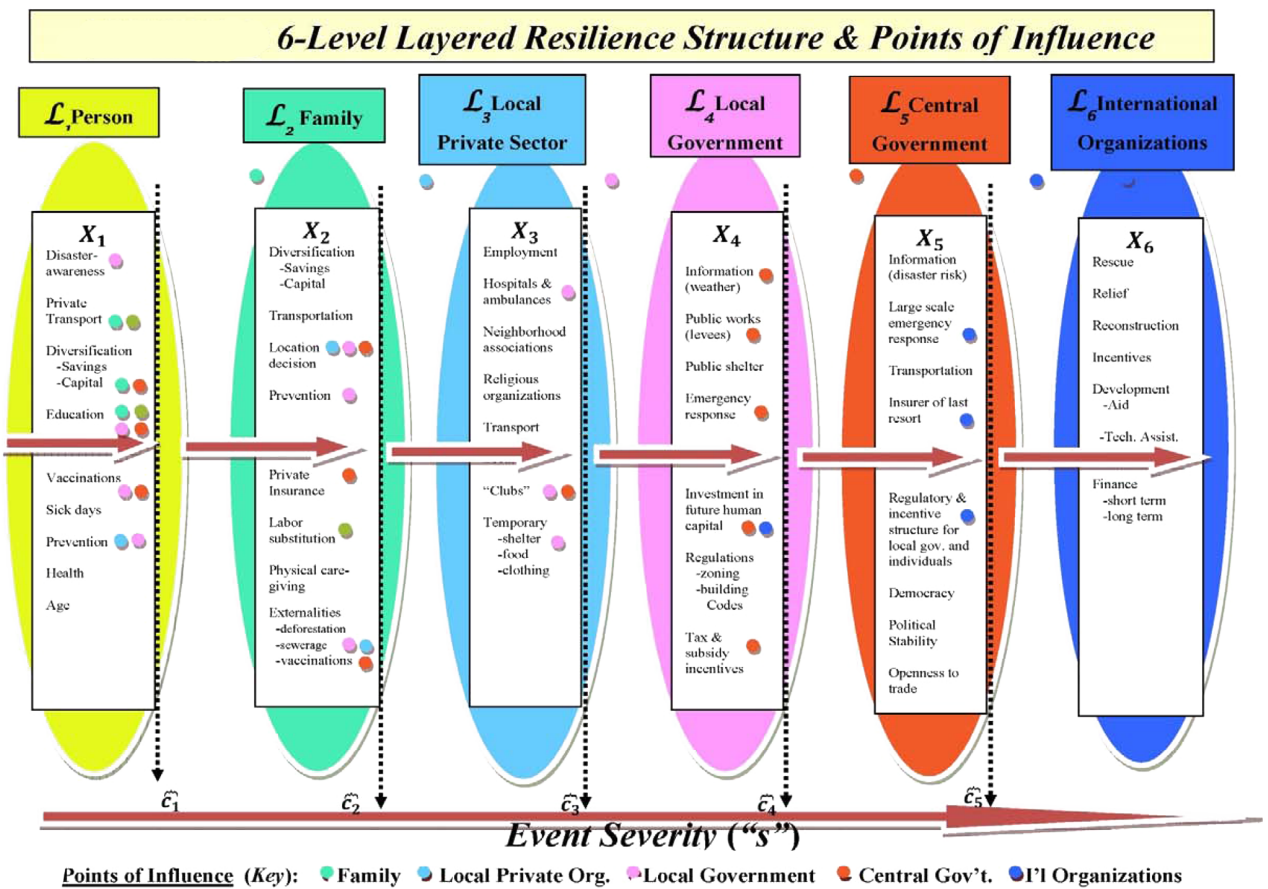

Figure 2. This figure illustrates the layered nature of resilience in human systems. Each layer is color-coded. The native resources $\left(X_{i}\right)$ that contribute to a given layer's resilience are listed below it. Colored dots represent influence points, places where higher layers of that color can influence the targeted layer by augmenting or complementing its native resources and thus contribute to its resilience. For instance the international community can influence the resilience of a central government by helping with emergency response and by acting as an insurer of last resort. In contrast the international community is likely to be much less effective in promoting democracy, even though democracy has been shown to contribute significantly to national disaster resilience.

Notice that an actor at layer " $k$ ", $1<k \leq n$ can affect lowerlevel actor capacity by retaining its own native resource $X_{k}$, or by injecting resources into a lower layer and thus augmenting $X_{l}(l<k)$. In the former case it would increase capacity of all actors below its own level $\forall j<k$, whereas in the latter case resource injections can be targeted differentially across lower-level actors.

By way of illustration, we may consider that the requirements for a resilience capacity function as in Eqs. (3) and (4) are satisfied by Cobb-Douglas technology, ${ }^{5}$ with elasticities $0 \leq \alpha_{i i} \leq 1$ and $0 \leq \alpha_{i(i+1)} \leq 1$. Starting at level 1 we would then write

$C_{1}=X_{1}^{\alpha_{11}} C_{2}^{\alpha_{12}}$

\footnotetext{
${ }^{5}$ The Cobb-Douglas function is the mathematical relation between inputs and output that is most widely used by economists. In addition to its simplicity, it has many other desirable properties, like allowing for the same level of output to be produced with an infinite number of input combinations and the fact that any input can be substituted for any other one, albeit only at a non-constant rate. The simplicity does come at the cost of imposing restrictions, including homotheticity and homogeneity, that may not be desired. The arguments developed in this section can also be developed with a much more general specification of production, but this would require a large amount of additional technical clutter without producing any significant additional insights.
}

Since a similar relation holds at level 2 we can write Eq. (6) as

$C_{1}=X_{1}^{\alpha_{11}} X_{2}^{\alpha_{12} \alpha_{21}} C_{3}^{\alpha_{12} \alpha_{22}}$

and so forth, recursively, until we eventually obtain

$$
\begin{aligned}
& C_{1}=X_{1}^{\alpha_{11}} X_{2}^{\alpha_{12} \alpha_{21}} X_{3}^{\alpha_{12} \alpha_{22} \alpha_{31}} X_{4}^{\alpha_{12} \alpha_{22} \alpha_{32} \alpha_{41}} \\
& X_{5}^{\alpha_{12} \alpha_{22} \alpha_{32} \alpha_{42} \alpha_{51}} \cdot \ldots C_{n}^{\alpha_{n 1} \prod_{i=1}^{(n-1)} \alpha_{i}}=\prod_{i=1}^{n} X_{i}^{\beta_{i}},
\end{aligned}
$$

where $\beta_{1}=\alpha_{11}$.

Upper levels affect resilience by decreasing time to recovery and/or by increasing capacity. In this model these two effects are brought about by changes in resilience technology, the $\alpha_{i i}$, and by increases in native resources, the $X_{i}$, respectively. They are depicted in Fig. 1 in relation to an initial resilience function $t_{i}^{0}\left(C_{0}, s\right)$. The function $t_{i}^{1}\left(C_{0}, s\right)$ has the same capacity as $t_{i}^{0}$ but a lower time to recovery (higher $\alpha_{i i}$ ) for any disaster with severity $s \leq C_{0}$. The function $t_{i}^{2}\left(C_{2}, s\right)$ shows what happens to $t_{i}^{0}$ when capacity is increased from $C_{0}$ to $C_{1}$.

These definitions of resilience and resilience layers can accommodate "building back better". This is the idea that the presence of mind, widespread publicity, sympathy, and even 
political vulnerability immediately following a disaster create a short-lived opportunity to invest in lowering future vulnerability. For instance Gallopín (2006) and Birkmann et al. (2013) split resilience into coping and adaptation. In the latter paper, coping deals with "the here and now capacity" and "with the conservation and protection of the current system and institutional settings". Adaptation refers to the "longerterm and constantly unfolding process of learning, experimentation and change" (p. 196). In the context of the model presented here, "capacity" is indeed the here and now capacity. It describes what will happen if a disaster strikes. But this does not preclude adaptation or advocate against building back better - quite the contrary. The model makes it clear where external layers can exert influence to change resilience, given the state of technology. It suggests that it may be possible to increase resilience by reallocating resources among actors. It also goes beyond this type of adaptation to indicate that the resilience technology (the $\alpha$ ) can itself be targeted for change.

Once the parameters are calibrated, the model can be used for policy simulations. For example Eq. (8) implies that upper-level resource impact is diluted as the resources move down the resilience chain. This follows from the assumption that $0 \leq \alpha_{i i} \leq 1$ and $0 \leq \alpha_{i(i+1)} \leq 1$. Assume that all of the elasticity parameters are $\alpha_{i j}=0.5$. This value is quite large, for it means that, if international (level 6) assistance were doubled, the central government's resilience capacity would rise by $41 \%$. Even so, this doubling of foreign aid increases individual citizen resilience by only $2 \%$ !

Another simple simulation can be performed. Suppose that every citizen in an afflicted country had USD 1 in native resilience capacity and that there are six levels in the system, as in Fig. 2. Foreign assistance of USD 1 per person is contemplated, enough to double individual prevention. Will it be more effective to spend it at level 5, the central level, or to augment individual capacity at level 1 ? The pre-donation individual resilience capacity is $C_{1}=X_{1}^{\alpha} X_{5}^{\beta}=X_{5}^{\beta}$, where coefficient subscripts are omitted for convenience. ${ }^{6}$ The first alternative that is contemplated is to increase individual native resources from USD 1 to USD 2, so that capacity at that level becomes $C_{1}^{a}=2^{\alpha} X_{5}^{\beta}$. The second alternative is to augment central government resources by $\$ \mathrm{~N}$, thereby increasing individual capacity to $C_{1}^{b}=X_{1}^{\alpha}\left(X_{5}+N\right)^{\beta}$. If the central government alternative is preferable, it must be true that $C_{1}^{a}<C_{1}^{b}$. After a few simplifications it can be shown that this implies that, in per capita terms, current central government native resources are $\frac{X_{5}}{N}<\frac{1}{2^{\frac{\alpha}{\beta}}-1}$. If we assume that $\alpha_{i j}=0.5$ as before, then $\beta_{5}=0.5^{5}$ and thus $2^{\frac{\alpha}{\beta}}-1=2^{16}-1=65535$. It will be preferable to use the money to augment the central government's resilience resources rather than to double individual resources only if the initial central govern-

\footnotetext{
${ }^{6}$ We may ignore the intermediate levels because they do not change, by assumption.
}

ment resilience expenditures per capita are extremely low, in fact less than USD 15 for every million people in the country $\left(\frac{X_{5}}{n}<\frac{1}{65535}\right)$. If current resilience expenditures are any higher than that amount, then the impact on resilience will be greater when the donation goes directly to individual capacity enhancement.

This model can be used to measure and compare resilience at any level - national, sub-national, and international. The level of recovery at time $t$ can be measured in terms of the initial, pre-event level of welfare. Any measure of collective resilience will involve a weighted aggregation of the recovery of system actors. Once the appropriate social welfare function $W\left(t_{i j}\right)$ is chosen, it can be used to aggregate individual actor resilience into a measure of national recovery and therefore of national resilience. However, as is usual with this sort of problem, the issue of choosing a social welfare function and aggregating individual resilience into a national measure will present thorny ethical challenges. The literature on poverty is one of the areas of study where the aggregation problem has been most carefully studied (for instance, Sen, 1976, 1979). The many ways to deal with the aggregation problem range from acknowledging it explicitly, as in Foster et al. (1984), to cleverly circumventing it, as in Atkinson (1987). In disaster analysis shortfalls need not be measured in reference to some exogenously determined benchmark like the poverty line. Indeed, in the present application post-disaster shortfalls are measured in relation to pre-event levels of welfare.

As a brief illustration of the aggregation problem, consider two weighting systems that are often used and look superficially similar. The first one is the average percentage recovery (APR), which measures individual recovery rates and then averages them. It is given by APR $=\frac{1}{n} \sum_{1}^{n} \frac{v_{i}^{t}}{v_{i}^{0}}$. The second measure is the overall percentage recovery (OPR), which aggregates individual post-disaster values and then compares them to the total pre-disaster value. It is given by $\mathrm{OPR}=\frac{\sum_{1}^{n} v_{i}^{t}}{\sum_{1}^{n} v_{i}^{0}}$.

These are actually very different measures. For instance, if the measure of disaster impact is economic losses, the OPR is strongly biased towards people who were at the upper end of the income distribution. This is because APR discounts the value of each person at any post-recovery time by their initial well-being, whereas OPR uses wealth of the entire group as a norm, regardless of its distribution. By way of example, suppose that all the citizens of a country live in either the poor city or the rich city. Before the disaster the poor city had wealth " $w$ " and the rich city had wealth $10 \mathrm{w}$. The disaster wipes out $75 \%$ of both cities' wealth, so that postdisaster wealth is $0.25 \mathrm{w}$ for the poor city and 2.5 for the rich city. Suppose that the rich city recovers more quickly, so that sometime after the disaster it is observed to have $90 \%$ recovery, with wealth $9 \mathrm{w}$, while the poor city is only at $50 \%$ recovery and wealth $0.5 \mathrm{w}$. The APR measure of national re- 
covery would be APR $=\left(\frac{\frac{0.5 w}{w}+\frac{9 w}{10 w}}{2}\right)=70 \%$, whereas the much more commonly used measure is OPR $=\left(\frac{0.5 w+9 w}{11 w}\right)=$ $86.4 \%$, strongly biased towards the higher recovery of the high income city. It is easy to imagine wanting the aggregate recovery measure to do just the opposite. In any case, once resilience is understood as a system, the economic optimization of the aggregation function is subject to aggregate resource constraints. Institutional constraints, such as limitations on transfers among actors at the same level, or even among levels, may also have to be included. The technical methods are well understood.

Finally, we must also admit game-theoretic considerations. If we write $X_{i}=X_{i}\left(X_{k}\right)$ and/or $X_{k}=X_{k}\left(X_{i}\right)$ for $i \neq k$, actors become players in a strategic allocation of resources.

\subsection{Summary to this point}

The insight provided by this model is that there are three ways to increase resilience. The first is to raise native resilience by injecting resources at any of the levels. A second method is to latch lower levels onto higher-level in-kind resources, as when a local government opens its buildings as temporary housing for displaced homeowners. The third way is to act on the technology of resilience, i.e., to target the resilience function itself for improvements in efficiency.

The model provides a foundation for categorizing policy interventions into short-, medium-, and long-term actions. In the short term the resilience system, its resources, and interactions among levels are immutable. The medium term is a planning horizon over which the resilience function technology is fixed, some native resources like education levels are fixed, but some native resources are variable. The long term is a planning horizon over which all native resources are considered variable. Native resources like education, health, population location, and building codes that are fixed in the short and medium terms become long-run influence points.

Because resources are diluted as they move down through the resilience system, it may be more cost effective in the long run for the upper-level actors to help actors at lower levels to build up their own native resources, their capacity to withstand disaster, and their recovery speed than to set aside resources for helping those same actors recover after disaster has already struck. This can often be done more economically through a program that leverages direct resource commitments with restructured institutional responsibilities and revamped design and enforcement of incentives and regulations.

Finally, the model developed here emphasizes the importance of taking a system-wide view of resilience. In contrast to the haphazard structures that emerge as de facto systems after a disaster, long-term planning can design entire systems so as to maximize resilience for the resources expended. This view recognizes the layered structure of response and builds on it by carefully assigning responsibility at each level, deter- mining coordinated interlevel relations, and designing incentive structures so that they are compatible with the optimal system design.

\section{Economic evidence of resilience: what works?}

This section explains how markets handle uncertain adverse events and why markets are nevertheless likely to fail in disasters. It also reports recent economic evidence on what does work - what does make countries, communities, businesses, and people more resilient to disasters. The empirical evidence clearly shows that there are layers of resilience to disaster. Section 4 will illustrate how the resilience model introduced in Sect. 2 can be used to organize this rapidly emerging body of data and how it can be assembled into a structured program of action.

\subsection{Why do markets fail disasters?}

Private markets have mechanisms for handling adverse events; however mounting evidence suggests that they do not perform this function well when they confront disasters. To understand why, it helps to first understand what private markets do do well.

What should be done when an adverse event strikes? In principle the answer is simple: draw down rainy-day funds. Informed economic decisions can be made even if there is uncertainty, as long as there are three pieces of information: (i) the amount of damage expected, (ii) the probability that this damage will occur, and (iii) the time paths of damages and probabilities.

Three examples - a house fire, college tuition payment, and old-age health care - with well-known solutions illustrate how these variables can differ and also how private markets arrange to incorporate these differences into a plan. (i) The probability that a randomly chosen house will catch on fire is well known and does not generally change over time. (ii) The need for college tuition is a well-known function of age, but the amount of tuition that will be needed is not known in advance (it depends on what school the child attends and on the financial aid grants). (iii) At some point everyone will have medical problems that deprive them of the ability to earn income. The exact time is unknown, but it is known that the likelihood rises with age.

Information on damage, probability, and the changes in these variables over time can be used to calculate the expected present discounted value, the basis for determining how many resources should be set aside to meet these needs. Insurance is chosen for the house fire because, though the probability is known, the timing is not. It would be risky to try to build up savings as a remedy, so homeowners bet the insurance company that their house will burn. The company gathers data on a large number of homes, calculates the probability of fire and expected damages, and prices the bet 
so that the company can not lose on average. In the second example, parents choose savings to meet expected minimum anticipated college tuition needs, because the time when tuition will be due is nearly certain. Above-minimum expenses can be borrowed and paid back once the student graduates and reaps the labor market returns from her education. In the third example a mixture of insurance and personal savings are used to provide for old age because the exact timing is unknown, as in the fire example, but it is known that the probability of needing extra resources grows with age, as in the college example.

The economics of disasters has settled on a definition of disasters as low-frequency, high-impact events (Kunreuther and Pauly, 2009). This places disasters outside the realm of adverse events that can be handled by private insurance and financial markets because the three key bits of information that are needed for rainy-day planning are missing. Calculating event probabilities, damages, and changes in these variables over time requires data on a large number of occurrences. The low frequency of disasters means that these data are not available. These missing data make disasters qualitatively different from adverse events that can be handled within existing financial frameworks (for instance, Camerer and Kunreuther, 1989; Horwich, 2000; Kahn, 2005; Berger et al., 2008, 2010; Tierney, 2008; World Bank, 2010; Keefer et al., 2011; Skidmore and Toya, 2013).

Disasters are also different because of recent evidence that climate change is increasing the frequency and intensity of natural disasters (Nordhaus, 2010; Emanuel, 2005). In fact, damages would increase even if the frequency and intensity were not expected to rise. Population growth, income growth, and the movement of population and physical capital to areas where disasters are more likely also conspire to increase the frequency and magnitude of disasters (Nordhaus, 2006; Kellenberg and Mobarak, 2008; Pielke et al., 2008).

Finally, the psychology literature suggests private markets will fail if people systematically misperceive disaster risk. Experimental evidence suggests that the rarity of disastrous events leads to over-discounting but that, when disaster actually strikes, people overestimate the likelihood that it will happen again (Khanemann et al., 1982; Tversky et al., 1988; Camerer and Kunreuther, 1989). Fielding (2012) examines flood risk awareness among people living in the flood plains of Wales and England and finds some evidence that risk is more likely to be underestimated if people are both poor and at high objective risk of flooding. This literature suggests that people may make the wrong decisions about disaster if left on their own.

\subsection{Why resilience differs across actors}

Economists are more inclined to see underinvestment in prevention and mediation as a problem that originates in the incentives created by the political system (Tierney, 2008) and the regulatory environment that it generates (World Bank,
2010; Keefer et al., 2011). Michel-Kerjan (2007) characterizes the "politician's dilemma", wherein politicians up for reelection spend on projects with immediate payoffs even though they know that investments in long-term prevention and mitigation are necessary. The immediate payoffs help them get re-elected, whereas disaster mitigation investments are more likely to benefit the next person in office.

This interaction between political structure and resilience emerges straightforwardly from the empirical literature in political science too. For instance, Healy and Malhotra (2009) analyze US 1984 to 2004 county-level data to examine the impact of spending on prevention versus disaster relief on election outcomes. They find that preparedness spending is effective: a $1 \%$ increase in preparedness spending is associated with a $0.134 \%$ reduction in disaster damage, whereas relief spending has no impact on future damage. They calculate that this amounts to a 15-to-1 return in Net Present Value (NPV) terms (p. 395, 6). And yet electoral impact is the opposite: preparedness spending has no effect, while relief spending increases votes for the incumbent party significantly.

Keefer, Neumeyer, and Plumper (2011) report supporting empirical evidence in the cross-country context, finding that earthquake death rates are lower in countries where earthquake propensity is higher and also in countries that are more democratic. They argue that this is because more frequent earthquakes increase the political payoff to enacting and enforcing stricter building codes and that this payoff is higher in democracies.

The guidance for linking a layered political structure with public-sector disaster-handling capacity can be sought in the economic theory of fiscal federalism. Oates (1972) argues for a layered structure of government based on economic incentives. Government functions in a democracy should be assigned to the lowest level of government which circumscribes all of the benefits and costs of those functions. The implication for disasters is clear. This would suggest that, since earthquakes have local impacts, building codes and the enforcement of these codes should be left to local jurisdictions because they have better information on local conditions and because this would internalize the costs and benefits of prevention. When disaster implications spill over into other jurisdictions, as is the case with flood control levees and nuclear power plant construction codes, interjurisdictional effects need to be handled by higher levels of government.

In the economic theory of democracy, the political system can even mimic the private sector's ability to deal with preference heterogeneity. If risk aversion is not uniformly distributed across the population, people can "vote with their feet", a process that economists call Tiebout sorting (Tiebout, 1956), and form a spectrum of communities that ranges from carefree to extremely risk-averse. Communities that collect risk-averse individuals would be distinguished by zoning that requires higher private and public spending on earthquake 
damage prevention and also by higher local taxes to pay for it.

Sociology sees inequalities in the distribution of exposure to disaster risk as arising mainly from social disadvantage and overt discrimination (for instance Fielding, 2012). In contrast, the local public finance models of economics would expect some variation in local risk exposure that is brought about by diversities of taste and incomes because the population sorts itself out by migrating, trading off risk exposure for lower rents, lower house prices, and lower local taxes. Inequalities in risk exposure that are correlated with income are not in themselves evidence of an economic (or social) problem, as long as there is good information about risk and property and insurance prices reflect the risk.

This body of economic theory is relevant to the design of resilient systems because it argues for circumspection in crafting and assigning all governmental responsibilities across levels of government in a layered federal system. It must therefore also apply to the assignment of roles in constructing disaster resilience. Responsibility for disasters can mimic the assignment of responsibility for other government services.

Empirical evidence backs up the notion that layered decision-making can be good for resilience. Kahn (2005) finds that - even after controlling for location, income, and other covariates - countries with more democratic governments suffer fewer earthquake deaths, a finding that is backed up by Noy (2009). Also, Skidmore and Toya (2013) examine data from 78 countries and find that more decentralized countries experience fewer of all disaster-related deaths. They also find a complementarity between educational attainment of the population and the degree to which decentralization reduces disaster deaths. Chernick and Haughwout (2008) describe the reaction to the $9 / 11$ attack on New York as a successful example of fiscal and economic resilience brought about by layers of cooperation among local, state, and central levels of government in the US federal system.

There are thus substantial theoretical arguments in favor of high local autonomy, and some of the empirical evidence appears to back up this theoretical guidance. Nevertheless, the absence of information about the extent of impact, the absence of information about disaster probability, and the failure of private insurance markets make the assignment of disaster responsibilities crucially different from other aspects of public-sector organization.

The work of several writers qualifies the positive assessment of how well decentralized democracies handle disasters. Berger et al. (2008), Wildasin (2008, 2011), Jaffee and Russell (2008), and others caution that recent US central government response to disasters is creating incentives for lax behavior on the part of local governments. They hold that the federal government's role has slipped past insurer of last resort to the point where it is now a de facto guarantor of post-disaster help. A separate and longstanding body of economic theory (Arrow, 1970; Zeckhauser, 1970) suggests that these implicit federal guarantees of help will be a disincentive for local government investments in prevention and will also dissuade individual citizens from spending on mitigation and insurance. Fannin et al. (2012) find empirical evidence that this has already affected American local government finance. They examine the fiscal health of local communities in Louisiana and Mississippi that were affected by hurricanes Katrina and Rita in 2005. Communities with good pre-storm fiscal health actually fared worse after the storm; their fiscal health deteriorated more than communities that started off in an inferior position. The authors conclude that local governments with better fiscal health were required to share more of the recovery burden, whereas those that had not prepared for disaster were bailed out. We will revisit this topic when we review proposals for action in Sect. 4.

In addition to political structure, the empirical literature on disaster economics also points to myriad country characteristics that have significant effects on disaster propensity and resilience. These include proximity to the Equator (closer is better!), distance from the "ring of fire", political corruption (Khan, 2005), frequency of disaster (Keefer et al., 2011), elevation, disaster type, ethnic fractionalization (Skidmore and Toya, 2013), the degree of economic development, equality of income distribution, literacy, openness to trade, foreign exchange reserves (Noy, 2008), the type of natural disaster, and the importance of agriculture to the economy (Fomby, et al., 2009). It is fairly easy to see how these can be categorized in the framework of Sect. 2: some of these are immutable native resources, while others are influence points that can be affected with conscious programmatic interventions.

Also, it is not only the real economic sectors that matter. Recent empirical work points to the crucial role played by private and public financial flows and by the replacement of capital in the speed of recovery after disaster. In fact, the body of literature supporting this fact is by far the most complete and convincing. It deserves to be reviewed on its own.

A few recent microstudies are forming a set of very interesting results on the importance of uninterrupted financial flows to individual recovery in three different contexts. Mohapatra, Joseph, and Ratha (2012) looked at worker remittances in sub-Saharan Africa. They found that remittances from family overseas increase after disaster and that this inflow has large and significant effects on the speed with which families recover.

De Mel, McKenzie, and Woodruf (2012) argue for the importance of restoring capital to microenterprises. They report the results of a controlled experiment in Indonesia. When the 2004 tsunami destroyed a large swath of coastal Indonesia, small firms and microenterprises lost their working capital. The line of demarcation for the authors' experiment was the exogenously determined line along which the tsunami's destructive invasion of land stopped. The authors sampled firms on either side of the line of destruction. Then they made small grants to a randomly selected subset of firms and observed the results. The grant-receiving firms that were wiped out 
by the tsunami were soon indistinguishable from firms that had not been affected by the tsunami at all. Similar tsunamiaffected firms that did not receive grants resorted to traditional, informal mechanisms - mostly personal savings and borrowing from friends and family. It took these non-grant firms twice as long to recover from the tsunami as the firms that received grants.

There are serious deficiencies with the mechanisms for replacing microenterprise capital post-disaster in developed economies too. Runyan (2006) studied US communities along the Gulf Coast in the weeks after Katrina. He found that business interruption was essential for small business owners and that delays in releasing Federal Emergency Management (FEMA) and Small Business Adminisreation (SBA) funds were the principal problem that businesses faced in recovering after the storm and thus in rebuilding downtown communities along the gulf.

This new empirical evidence on the importance of postdisaster finance becomes particularly worrisome because it is arising at a time when insurance companies have begun to seriously restrict their coverage of disasters (Kunreuther and Pauly 2009). The current mechanism for re-injecting capital into an economy that has been hobbled by disaster is a very good example of an ad hoc multilevel resilience mechanism that cries out for a policy fix.

The need for a multilevel approach to disasters is especially evident in the role played by the insurance industry. Insurers fear the liquidity crisis that can arise when disaster strikes (Jaffee and Russell 2008). Experience has shown them that their claims liability can exceed the insurance companies' current revenues, what we would call their capacity in this model. Insurance companies have traditionally covered themselves against unexpectedly large outflows of funds by buying contracts from reinsurance companies. But the "Re" market recently has begun refusing to cover acts of terrorism and many other catastrophic disasters. So these two layers of private system support fail and, once again, the burden tends to fall on the public sector because "individual citizens and voters may have expectations that, if they suffer a catastrophic loss, someone will provide ex post compensation" (Jaffee and Russell 2008, p. 38).

Wildasin (2008) points to a very similar problem in US intergovernmental relations. The federal government is charged with disaster relief because disasters can affect many localities, because it has more resources at its disposal, and because of implicit risk sharing among states within the union. Wildasin notes that these roles appear to be consistent with fiscal federalism framework, and yet assigning all disaster responsibility to the federal government provides little incentive for states to invest resources or political capital in policies and measures that lower disaster risk. Federal government liabilities can therefore be expected to grow until they become untenable, as they do in the insurance case studied by Jaffee and Russell.
In summary, recent literature on the economics of disasters highlights many factors that affect national resilience. All of these results are informative and interesting in their own right but are currently unconnected. The framework proposed in this paper pieces these results into a comprehensive model than can organize and explain them. People recover more quickly from disaster when they have relatives that live overseas: this is a resilience link between individuals and their family; the family's influence point is remittances, and a policy intervention is to facilitate the flow of private funds after disaster. Business activity recovers more quickly when small businesses have access to capital: this is a resilience link between local businesses, local government, perhaps national capital markets; the influence point is capital, and a policy intervention is rapid response commercial loans guaranteed by local governments. Communities recover more rapidly when there is more local control over resources: this is a resilience link between local governments and the central government; the influence point is the local government incentives to invest in mediation, and a policy response is local ownership of some disaster funding and local allocation of some responsibility for spending it. Countries that are more open to trade and less dependent on agriculture recover more quickly: this points to a resilience link between countries and the international community; the influence point is economic diversification and a policy intervention that encourages nontraditional manufactured exports. As a whole, the recent literature provides support for the existence of multiple layers of response. Within each level actors can differ in many characteristics that affect their resilience. Some of the characteristics are fixed, native resources that can not be changed. But many of them are variable influence points which can be incorporated into a policy framework for a long-term national resilience enhancement program.

\section{Building resilience}

The literature on the economics of disaster provides empirical evidence that capacity and recovery speed vary and that the layered nature of resilience exists in our society. What would a set of policy recommendations look like if we put some meat on the bare-bones theoretical framework that is developed in this paper? In this section I illustrate what a fully developed resilience system might look like by developing a prototype of the financial sector as an example. Readers should bear in mind that this is an illustrative example and that similar multilayered resilience structures can be built for health, sanitation, education, transportation, mental health, and all the other aspects of welfare that may be damaged by disasters.

The most widely studied and best-understood mechanisms for recovery from disaster involve the financial sector. Financial resistance to and recovery from disaster lay bare the layered structure of resilience. Private flows from family mem- 
bers are key determinants of individual resilience to disaster. The ability to replace capital is key to private microenterprise resilience. Democracy, decentralized public decisionmaking, and relations among levels of government are key to public-sector recovery. Equally important is the layered relationship between private actors, insurance firms, reinsurers, and the central government. We know a great deal about these pieces of financial resilience, but these pieces have not been assembled into a coherent whole. I will next use what we know about all of these components of financial resilience to illustrate how a fully layered system of resilience might be constructed so as to maximize resilience of the system as a whole.

The first component is the insured-insurance-reinsurance system described in Jaffee and Russell (2008). In my framework, I would say that the government is serving as a fourth level actor. People (or businesses) comprise the first level, insurance companies the second level, the $R e$ market makes up the third one, and the federal government is the sole actor - albeit an informal actor - at the fourth and top level. The problem that Jaffee and Russell identify is that the government's role is informal and that reimbursements made under the current framework create a serious moral hazard problem which contributes to the central government's exposure, threatening to exceed its capacity to help. Also, expecting the government to reimburse all disaster losses is an untenable solution. Jaffee and Russell point out that the federal government has successfully prevented bank runs by guaranteeing liquidity and suggest that it could play a similar role in insurance markets. They propose government-guaranteed short-term (2 to 3-year) loans to reinsurers in the event that catastrophic losses exceed reinsurer liquidity constraints.

Independently of Jaffee and Russell (2008), Wildasin (2008) suggests that a similar set of problems inherent in the intergovernmental fiscal handling of disasters might be overcome by obligating the states to keep rainy-day funds. Every state would own a mandatory fund in an amount determined by an actuarially fair assessment of expected disaster damage, and the federal government would oversee disbursements from these funds. Wildasin proposes mimicking the mechanism that has worked in private health insurance. In the event of a disaster, states would pay a deductible out of their own reserve fund, up to some maximum level. After that, they would pay a predetermined fraction of additional expenses up to a second ceiling. The federal government would pay $100 \%$ of additional expenses above the second ceiling. This would preserve the central government's role as helper of last resort but reduce its exposure and also provide states with an incentive to invest in disaster mediation.

The model in this paper recognizes the Jaffee and Russell proposal and the Wildasin proposal as two pieces of a single resilience system. The first of these suggests formalizing a link between the private market as an actor and national government, while the second one proposes doing the same when local governments are seen as the level of actors below the national level. Both proposals identify financial resources as an influence point, and both recommend targeting incentives and rationalizing the flow of funds as a policy intervention to increase resilience. Within the context of this paper it is clear that both proposals would have to be coordinated as parts of a central government resilience strategy within a system-wide resilience framework. It is also clear that many more pieces are needed before the national resilience framework is complete. The task now is to envision what a complete resilience strategy looks like.

Consider a financial contingency system with three components. First, require people and businesses to carry private insurance, and also create incentives for savings as a pecuniary buffer against adversity. Incentives for savings and insurance that are specifically for this purpose can be built into the tax code, and they can be differentiated according to place of residence and risk exposure. When losses exceed insurance policy deductibles, insurance companies reimburse customers for the excess. Insurance companies themselves have reserves against loss, and also hold reinsurance policies for events that exceed their ability to pay while remaining financially viable. Reinsurers have reserves to meet these catastrophic losses, but only up to a ceiling. The government steps in with short term loans when losses exceed the ceiling, as proposed by Jaffee and Russell (2008). I propose extending this model to a global scale and including developing countries by having the World Bank guarantee short-term loans to countries when losses exceed their capacity. The World Bank would set up an international disaster contingency fund (IDCF) for this purpose of private insurance system solvency. A country could obtain an IDCF guarantee under the condition that it set up a World Bank-managed country disaster contingency fund (CDCF) of its own for providing liquidity to reinsurers. The size of the CDFC should depend on each country's exposure to disaster risk. The World Bank IDCF can be covered out of current member contributions, or out of an additional contribution to set up the IDCF.

Second, cover public losses by similarly extending Wildasin's (2008) proposal. Local governments would be required to set up an actuarially fair local disaster contingency fund (LDCF) that is owned by the local government but regulated by the central government. It would cover emergency response and shelter expenses, as well as the repair and replacement of roads, sewers, and other public goods damaged by disaster. Payment out of the LDCF would be subject to a ceiling that acts as a deductible. If the deductible is surpassed, the central government would step in with fractional funding as Wildasin proposes. I would add that the funding should be drawn out of that nation's own CDCF. This could be the same CDCF as in the previous paragraph, or a second contingency fund exclusively for the public sector. Furthermore, I suggest extending the scope of this mechanism beyond the individual country level by linking it to the CDFC. The national government would be required to augment its CDFC to cover local government disaster expenses. Central 
government expenditures for this purpose would be subject to their own deductible limit which, when exceeded, would entitle it to draw from the World Bank's IDCF. ${ }^{7}$

The first two parts of this financial resilience system can go a long way in covering the repair of private and public physical infrastructure that can be covered by insurance and by intergovernmental flows. But the financial damage of disaster goes well beyond physical structures. It includes interruption of income streams from personal injury, from job loss, from the destruction of crops and livestock in rural areas, and the destruction of private capital and loss of business income flows in the urban areas.

Third, prioritize the recovery of mechanisms for private financial flows following disaster. The empirical literature on the economics of resilience points to the critical role played by restoring financial flows not just between levels of government or from international organizations, or even between insurers and their clients, but to all levels. This means planning for grants and guaranteed loans to small businesses in the retail sector covered by additional tranches in the LDCF, CDCF, and IDCF funds. Finally, recovery programs would prioritize restoring automated teller machines (ATMs), bank branches, and money wire services to ensure that private remittances from family members overseas are able to reach victims of disaster.

These extensions of earlier proposals expand coverage to the international level and force the planning agencies at all levels to consider the financial implications of formally extending public obligations simultaneously in all areas affected by disasters. They also explicitly recognize the importance of "informal" flows between lower-level actors, flows that the theoretical model suggests probably play a crucial role in system-wide resilience.

\section{Conclusions}

Resilience is a new concept in the context of disasters. It arose naturally from observing that disasters of a similar magnitude affect various human populations differently. Resilience describes the ability to survive disasters and the speed of return to the pre-disaster state. The concept is related to the meaning of resilience in ecology, but it has to be modified before it can be useful to describe human populations. This paper has proposed such a modification and has stated the definition of resilience succinctly in a form that can be expressed mathematically. The model of resilience developed in Sect. 2 describes a system in which each person belongs to levels, groups of hierarchically organized subsets of the population. Each level has a native capacity to withstand adversity and a native recovery speed which depend on resources within that level. This relation can be described by a resilience function. Each level is also connected to levels

\footnotetext{
${ }^{7}$ Alternatively, a second set of CDFC-2 and IDCF-2 funds could be created specifically for public-sector disaster expenses.
}

above it through access points. These are entry ports through which higher levels can inject additional resources to leverage resilience, increasing capacity to survive disaster and disaster recovery speed. This framework can be stated formally with sufficient precision to make it useful for simulation and empirical policy analysis.

Being able to withstand disaster and to recover from it depends on having a resilient financial system, as well as on having incomes that are high enough to divert some resources to prevention, on having sufficient education to understand the consequences of not preparing for disaster, and on having a democratic system of government that is capable of gauging and responding to the citizen concerns. We also know that health, sanitation, transportation, and education are essential; that geographic location, building codes, and structural engineering are important; and that economic diversification, economic incentives, and income distribution matter.

The model developed here provides an analytical framework for simulation and for thinking about the structure of resilience: resilience capacity, the resilience function, native resilience, and systemic resilience are linked in a multilevel system. The framework was illustrated with an example of financial resilience, but more work is needed to understand all of these mechanisms and to design similarly layered systems of responsibilities and incentives in health, education, transportation, and elsewhere. We need to better understand the organization of actors into resilience layers, the relationship between these layers, and the entry points where policy can make a difference. Only when this is done, when we are able to view all of the sectorial plans at once, can we consider that we have a fully integrated framework for increasing resilience and confronting the rise in disaster severity and disaster frequency that science tells us to expect imminently.

Acknowledgements. I would like to acknowledge the helpful suggestions of Elizabeth Berger, Ky Luu, and Apollo Nkwake and two anonymous referees. Any remaining errors are my own.

Edited by: T. Glade

Reviewed by: two anonymous referees

\section{References}

Arrow, K.: Essays in the Theory of Risk-Bearing, North-Holland Publishing Company, Amsterdam, 1970.

Atkinson, A.: On the measurement of poverty, Econometrica, 55, 749-764, 1987.

Birkmann, J., Cardona, O. D., Carreño, M. L., Barbat, A. H., Pelling, M., Schneiderbauer, S., Kienberger, S., Keiler, M., Alexander, D., Zeil, P., and Welle, T.: Framing vulnerability, risk and societal responses: the MOVE framework, Nat. Hazards, 67, 193-211, 2013. 
Cabot-Venton, C. C., Fitzgibbon, C., Shitarek, T., Coulter, L., and Dooley, O.: The Economics of Early Response and Disaster Resilience: Lessons from Kenya and Ethiopia, Department for International Development (DFID), United Kingdom, 2012.

Calvo, C. and Dercon, S.: Measuring Individual Vulnerability, Economics Series Working Papers 229, University of Oxford, Department of Economics, available at: http://www.economics. ox.ac.uk/materials/working_papers/paper229.pdf (last access: 20 January 2014), 2005.

Camerer, C. F. and Kunreuther, H.: Decision processes for low probability events: policy implications, J. Policy Anal. Manag., 8, 565-592, 1989.

Carter, M. R., Little, P., Mogues, T., and Negatu, W.: The LongTerm Impacts of Short-Term Shocks: Poverty Traps and Environmental Disasters in Ethiopia and Honduras, BASIS Brief No. 28, Collaborative Research Support program, Department of Agricultural and Applied Economics, University of Wisconsin, Madison, 2005.

Carter, M. R., Little, P., Mogues, T., and Negatu, W.: Poverty traps and natural disasters in Ethiopia and Honduras, World Dev., 35, 835-856, doi:10.1016/j.worlddev.2006.09.010, 2007.

Chernick, A. F. and Haughwout, H.: Economic resilience, fiscal resilience \& federalism, in: Risking House and Home, chap. 8, edited by: Quigley, J. and Rosenthal, L., Berkeley Public Policy Press, Institute of Governmental Studies Publications, Berkeley, California, 39-59, 2008.

Cohen, C. and Werker, E. D.: The political economy of "natural" disasters, J. Conflict Resolut., 52, 795-819, 2008.

De Mel, S., McKenzie, D., and Woodruff, C.: Enterprise recovery following natural disasters, Econ. J., 122, 64-91, 2012.

Elliott, M. and Quintino, V.: The estuarine quality paradox, environmental homeostasis and the difficulty of detecting anthropogenic stress in naturally stressed areas, Mar. Pollut. Bull., 54, 640-645, 2007.

Emanuel, K.: Increasing destructiveness of tropical cyclones over the past 30 years, Nature, 436, 686-688, 2005

Fannin, J. M., Barreca, J. D., and Detre, J. D.: The role of public wealth in recovery and resiliency to natural disasters in rural communities, Am. J. Agr. Econ., 94, 549-555, 2012.

Fielding, J. L.: Inequalities in exposure and awareness of flood risk in England and Wales, Disasters, 36, 477-494, 2012.

Foster, J., Greer, J., and Thornbecke, E.: A class of decomposable poverty measures, Econometrica, 52, 761-766, 1984.

Frankenberger, T., Spangler, T., Nelson, S., and Langworthy, M.: Enhancing Resilience to Food Security Shocks in Africa, TANGO International, 2012.

G\&C Merriam and Co: Webster's Unabridged Dictionary of the English Language, Springfield Massachussets, 1971.

Gallopín, G.: Linkages between vulnerability, resilience, and adaptive capacity, Global Environ. Change, 16, 293-303, 2006.

Gunderson, L.: Resilience, flexibility and adaptive management antidotes for spurious certitude?, Ecol. Soc., 3, 7, 1999.

Gunderson, L., Holling, C. S., Pritchard, L., and Peterson, G. D.: Resilience in Ecosystems, Institutions, and Societies, Beijer Discussion Paper Series No. 95, Beijer International Institute of Ecological Economics, The Royal Swedish Academy of Sciences, 1997.

Horwich, G.: Economic lessons of the Kobe Earthquake, Econ. Dev. Cult. Change, 48, 521-541, 2000.
Kahnemann, D., Slovic, P., and Tversky, A.: Judgment under Uncertainty: Heuristics and Biases, Cambridge University Press, New York, 1982.

Kahn, M.: The death toll from natural disasters, Rev. Econ. Stat., 87, 271-284, 2005.

Keefer, P., Neumeyer, E., and Plumper, T.: Earthquake propensity and the politics of mortality prevention, World Dev., 39, 15301541, 2011.

Kellenberg, D. K. and Mobarak, A. M.: Does rising income increase or decrease damage risk from natural disasters?, J. Urban Econ., 63, 788-802, 2008.

Khun, T. S.: The Structure of Scientific Revolutions, Univ. of Chicago Press, 1962.

Kunreuther, H. and Pauly, M.: Insuring Against Catastrophes, Risk Management and Decision Processes Center, The Wharton School of the University of Pennsylvania, April 2009, 2009.

Hallegatte, S. and Przyluski, V.: The Economics of Natural Disasters: Concepts and Methods, World Bank Policy Research Working Paper No. 5507, available at: http://elibrary.worldbank.org/ doi/pdf/10.1596/1813-9450-5507, 2010.

Healy, A. and Malhotra, M.: Myopic voters and natural disaster policy, Am. Polit. Sci. Rev., 103, 387-406, 2009.

Jaffee, D. and Russell, T.: Financing catastrophe insurance, in: Risking House and Home, edited by: Quigley, J. and Rosenthal, L., Berkeley Public Policy Press, Institute of Governmental Studies Publications, Berkeley, California, 37-46, 2008.

Levine, S., Pain, A., Bailey, S., and Fan, L.: The Relevance of "Resilience"?, Human Policy Group Policy Brief \#49, available at: http://www.odi.org.uk/sites/odi.org.uk/files/ odi-assets/publications-opinion-files/7818.pdf (last access: 15 January 2014), 2012.

McAslan, A.: The concept of resilience, understanding its origins, meaning and utility, Torrens Resilience Institute, available at: http://sustainablecommunitiessa.files.wordpress.com/2011/06/ community-resilience-from-torrens-institute.pdf (last access: 20 July 2014), 2010.

Meadows, D. H., Meadows, D. L., Randers, J., and Behrens, W. W.: The Limits to Growth: a Report for the Club of Rome, Universe Books, New York, NY, 1972.

Nordhaus, W.: Geography and macroeconomics: new data and new findings, P. Natl. Acad. Sci. USA, 103, 3510-3517, 2006.

Nordhaus, W.: The economics of hurricanes and implications of global warming, Clim. Change Econom., 1, 1-20, 2010.

Noy, I.: The macroeconomic consequences of disasters, J. Dev. Econ., 88, 221-231, 2009.

Oates, W. E.: Fiscal Federalism, Harcourt Brace Jovanovich, New York, 1972.

Pielke Jr., R. A., Gratz, J., Landsea, C. W., Collins, D., Saunders, M. A., and Musulin, R.: Normalized hurricane damages in the United States: 1900-2005, Nat. Hazards Rev., 9, 29-42, 2008.

Ravallion, M.: Expected poverty under risk-induced welfare variability, Econ. J., 98, 1171-1182, 1988.

Runyan, R. C.: Small business in the face of the crisis: identifying barriers to recovery from a natural disaster, J. Contingen. Crisis Manage., 14, 12-26, 2006.

Sen, A.: Poverty: an ordinal approach to measurement, Econometrica, 44, 219-231, 1976. 
Sen, A.: Issues in the Measurement of Poverty, Scan. J. Econom., 81, 285-307, 1979.

Thieken, A. H., Mariani, S., Longfield, S., and Vanneuville, W.: "Preface: Flood resilient communities - managing the consequences of flooding, Nat. Hazards Earth Syst. Sci., 14, 33-39, doi:10.5194/nhess-14-33-2014, 2014.

Tierney, K.: Hurricane Katrina catastrophic impacts and alarming lessons, in: Risking House and Home, chap. 7, edited by: Quigley, J. and Rosenthal, L., Berkeley Public Policy Press, Institute of Governmental Studies Publications, Berkeley, California, $119-138,2008$.

Tiebout, C.: A pure theory of local expenditures, J. Polit. Econ., 64, 416-424, 1956.

Tversky, A., Shmuel, S., and Slovic, P.: Contingent weighting in judgment and choice, Psychol. Rev., 95, 371-384, 1988.

UNDP Drylands Development Center: Community Based Resilience Assessment (CoBRA) Conceptual Framework and Methodology, available at: http://www.disasterriskreduction.net/fileadmin/user_upload/drought/docs/CoBRA Conceptual Framework.pdf (last access: 1 August 2013), 2013.

United Nations: Conference on Sustainable Development, available at: http://www.uncsd2012.org/history.html (last access: 23 July 2014), 2012.
USAID: Resilience, available at: http://www.usaid.gov/resilience (last access: 8 August 2013), 2013a.

USAID: The Resilience Agenda, available at: http://transition usaid.gov/resilience/ResilienceAgenda2Pager.pdf (8 August 2013), 2013b.

G\&C Merriam and Co: Webster's Unabridged Dictionary of the English Language, Springfield Massachussets, 1971.

Wildasin, D.: Disaster policies some implications for public finance in the U.S. Federation, Public Finance Rev., 36, 497-518, 2008.

Wildasin, D.: Disaster Avoidance, Disaster Relief, and Policy Coordination in a Federation, mimeo, Martin School of Public Policy, University of Kentucky, 2011.

Zeckhauser, R.: Medical insurance: a case study of the trade-off between risk spreading and appropriate incentives, J. Econ. Theory, 2, 10-26, 1970.

Zentner, N. A., Humbert, N., and Viallet, E.: Numerical Calculation of Fragility Curves for Probabilistic Seismic Risk Assessment, 14th World Conference on Earthquake Engineering, 12 17 October 2008, Beijing, China, available at: http://www.iitk. ac.in/nicee/wcee/article/14_05-01-0246.PDF (last access: 8 August 2013), 2008. 